\title{
RESULT OF ESWL IN THE MANAGEMENT OF URINARY STONES, IN THE DEPARTMENT OF UROLOGY, CHITTAGONG MEDICAL COLLEGE HOSPITAL: A STUDY OF 500 CASES.
}

\author{
Mohammed Jahangir Hossain ${ }^{1}$
}

\begin{abstract}
This was a prospective comparative study carried out in the Urology Department of Chittagong Medical College Hospital, Chittagong between the period of August 2007 to September 2008 to evaluate the result of ESWL in the management stones located in different parts of urinary tracts. Patients were selected from out patient department of $\mathrm{CMCH} \&$ treated as outdoor patient under injectable NSAID. Total 500 paticnts were included in the study. Ages of the patients ranged from 18 to $65 y r s$, with a mean age of $41.5 y$ rs. Of them 390 patient were male $(78 \%)$ and 110 patient $(22 \%)$ were female. The size of the stone ranged from 7 $\mathrm{mm}$ to $40 \mathrm{~mm}$ with a mean of $23.5 \mathrm{~mm}$. Of the 500 cases 400 cases were of Renal stone ( $80 \%$ ) and 100 Cases were ureteric stone ( $20 \%$ ). Of the 400 cases of renal stones 320 cases were totally fragmented( $80 \%$ ) in the first session and rest of the renal stones were totally fragmented in the second session, so the success rate at is $80 \%$ in 1 st session and $100 \%$ in 2 nd session.Among the 100 cases of Ureteric stones 70 cases were fragmented totally in the 1 st session, so the success rate is $80 \%$ in 1 st session and $20 \%$ were fragmented in subsequent session.But $10 \%$ of ureteric stones failed to fragment.
\end{abstract}

Keywords: ESWL; Urinary stones

\section{Introduction}

Stone diseases are as old as civilization. It was first identified in the Egyptian mummy of 4800 BC5 .It is third most common affliction of the Urinary tract6. In our country though we have no statistics, in USA $2-3 \%$ of total population suffer from Urinary stone diseases. Accordingly in Bangladesh about 42-45 millions of people are suffering from Urinary stone diseases. In Bangladesh it is more common in northern part of the country affecting predominantly

1. Assistant Professor of Urology Chittagong Medical College, Chittagong

2. Assistant Professor of Anesthesiology Chittagong Medical College, Chittagong

3. Post Graduate Student of MS (Urology) Chittagong Medical College, Chittagong

Correspondence : Dr Md Jahangir Hossain

\author{
Md Nizam Uddin ${ }^{2} \quad$ Md Saiful Islam ${ }^{3}$
}

male over female with a ratio of $3: 15$.

Extracorporeal shock wave lithotripsy:is a technique for shattering stones such as kidney stones or gallstones with a shock wave produced outside the body ${ }^{1}$.

The first use of shock wave lithotripsy to destroy kidney stones was in 1980 . Within a few years, it became the standard treatment for renal stones. Shock wave lithotripsy of gallstones began in 1985 . Although it worked well in patients with a single small stone, the method did not gain wide acceptance because of difficulty in clearing the fragments and the tendency to new stone formation. Treatment of stones in the common bile duct, pancreatic duct, and salivary gland has gained general acceptance. Extracorporeal shock wave lithotripsy is also known as ESWL.

The study was carried out between the periods of August 2007 to September 2008. 500 cases were included in the study.

\section{Aims and objectives}

1. The study was carried out to find the result of ESWL for stones located in different parts of Urinary tract.

2. To find the efficacy of ESWL for Ureteric stones in comparison to Renal stones.

3. To find out the result of ESWL for lower ureteric stones in comparison with upper ureteric stones.

4. To compare the result of Ultrasound with that of $\mathrm{C}$-arm in localizing urinary stones.

5. To find out the result of ESWL in case of large stones ( $>2 \mathrm{~cm}$ ).

\section{Methodology}

Patient attending in the Outpatient department of Urology Department, Chittagong Medical College \& Hospital with urinary stones were selected for the study. After detail history and clinical examination, patients were evaluated for stone disease. Estimation of serum creatinine \& Intravenous urography done as a routine in all the patient to see the gross renal function and distal obstruction. For larger stones in the majority of cases precise focus were used but for 
smaller stones extended focus were used.Criteria of stone clearance is to have no distal obstruction in any form.It is assessed in this study by doing intravenous urogram \& Uitrasonography of KUB \& Prostate with PVR.If there was any residual stone after 2 weeks of adequate $\&$ appropriate treatment as revealed by plain X-ray KUB , second session ESWL was planned.

\section{Inclusion criteria}

1. Any' renal and ureter stone less than $4.0 \mathrm{~cm}$ size having no distal obstruction and renal failure.

2. Stones at any level of the ureter without distal obstruction.

\section{Exclusion Critera}

1. Any stag horn calculus.

2. Stones larger than $4 \mathrm{~cm}$

3. Stones with distal obstruction

4. Stones with chronic renal failure

5 . Urinary bladder stones

6. Abdominal aortic aneurysms,

7.uncontrollable bleeding disorders

8. Pregnancy

9. Patient with cardiac pacemakers should be evaluated by a cardiologist familiar with ESWL . A cardiologist may need to be present during the ESWL procedure in the event the Pacemaker needs to be overridden.

In all the patient Urinalysis and culture sensitivity were done to exclude urosepsis.All the patient were advised to take light diet at previous night of ESWL. Prophylactic antibiotic, usually 3rd generation cephalosporin are used in all the patient. Adequate analgesic in the form of Injection ketorolac is used in all these patient. Stenting were not done as a routine procedure, done only in patients with huge stone bulk. For renal stone patient was laid supine but for lower ureteric stone patient was laid prone over the ESWL table .Stones were brought into view by moving the table Up and down (300) i.e. along the Y-axis or front / back or head /foot direction (00) ie along $\mathrm{X}$-axis.All these movements are controlled by Computerized digital control unit. Stones are brought into focus and targeted either by using $\mathrm{C}$ arm fluoroscopy or by ultrasound. Then after bringing the stone into focus, briefing the details of shock wave shockwaves are started. Shockwaves are started beginning from energy level 0.5 level. Which is raised gradually 0.1 levels for every 10 shockwave till 1.0 energy level. Then for every 20 shockwave 0.5 unit energy level is raised successively according to the need and tolerance of the patient. Maximum energy level used in this study was $7 \mathrm{kv}$ and minimum energy level used is $2 \mathrm{kv}$ and maximum no of shock wave used were 4500 shockwave.

\section{Results}

Total 500 patients were included in the study. The ages of the patient ranged from 18 to $65 \mathrm{yrs}$, with a mean age of $41.5 y$ rs. Of them 390 patient were male ( $78 \%)$ and 110 patient $(22 \%)$ were female. The size of the stone ranged from $7 \mathrm{~mm}$ to $40 \mathrm{~mm}$ with a mean of $23.5 \mathrm{~mm}$. Of the 500 cases 400 cases were of Renal stone $(80 \%)$ and 100 Cases were ureteric stone $(20 \%)$. Of the 400 cases of renal stones 320 cases were totally fragmented $(80 \%)$ in the first session and rest of the renal stones were totally fragmented in the second session, so the success rate at is $80 \%$ in 1 st sesion and $100 \%$ in 2 nd session. Among the 100 cases of Ureteric stones 70 cases were fragmented totally in the 1st session, so the success rate is $70 \%$ in 1 st session and $20 \%$ were fragmented in subsequent session.But $10 \%$ ureteric stone were unable to break. Only the adult group of patients were included in this study.

Table I : Age distribution among patients of this series ( $\mathrm{n}-500)$

\begin{tabular}{|l|c|c|c|c|}
\hline Type of stones & $\begin{array}{c}\text { No of } \\
\text { patient }\end{array}$ & $\begin{array}{c}\text { Age } \\
\text { range }\end{array}$ & $\begin{array}{c}\text { Average } \\
\text { Age }\end{array}$ & $\begin{array}{c}\text { Percentage } \\
\text { of total pt. }\end{array}$ \\
\hline Renal stone & 400 & $18-65 y r s$ & $41.5 y r s$ & $80 \%$ \\
\hline Ureteric stone & 100 & $20-65$ & $42.5 y r s$ & $20 \%$ \\
\hline Total & 500 & & & $100 \%$ \\
\hline
\end{tabular}

Among the 500 patient of this study 370 patients were male and 130 patients were female. The ratio is about 3: 1 .

Table II : Sex distribution among patients of this series(n-500)

\begin{tabular}{|l|r|c|c|c|}
\hline Type of stones & Male & Female & Total & Percentage \\
\hline Renal stone & 300 & 100 & 400 & $80 \%$ \\
\hline Ureteric zones & 70 & 30 & 100 & $20 \%$ \\
\hline Total & 370 & 130 & 500 & $100 \%$ \\
\hline
\end{tabular}

Out of 400 patients of Renal stone 320 patients that is $80 \%$ fragmented in the 1 st session. So the success rate is $80 \%$. Among rest 80 stones, all of them are fragmented in second session, so the success rate after 2 nd session is $100 \%$. 
Table III : Success rate of renal stone fragmentation $(n=500)$

\begin{tabular}{|l|c|c|c|}
\hline $\begin{array}{l}\text { Period of } \\
\text { ESWL }\end{array}$ & No of cases & $\begin{array}{c}\text { Totally } \\
\text { fragmented }\end{array}$ & $\begin{array}{c}\text { Success } \\
\text { rate }\end{array}$ \\
\hline 1st session & 400 & 320 & $80 \%$ \\
\hline 2nd session & 80 & 80 & $100 \%$ \\
\hline Total & 480 & 400 & $100 \%$ \\
\hline
\end{tabular}

Among the 100 ureteric stones, 80 stones are fragmented in 1st session. Among rest 20 patients, 10 are fragmented in 2 nd session, and rest 10 in $3 \mathrm{rd}$ session.

Table IV : Result of location of stones within kidney

\begin{tabular}{|l|c|c|c|c|}
\hline $\begin{array}{l}\text { Location } \\
\text { of stone }\end{array}$ & $\begin{array}{c}\text { No of } \\
\text { stone }\end{array}$ & $\begin{array}{c}\text { No of } \\
\text { total frag }\end{array}$ & $\begin{array}{c}\text { No of } \\
\text { cleared } \\
\text { stone }\end{array}$ & $\begin{array}{c}\text { Percentage } \\
\text { of } \\
\text { clearance }\end{array}$ \\
\hline Upper calyx & 300 cases & 300 cases & 300 cases & $100 \%$ \\
\hline Middle calyx & 150 cases & 150 cases & 150 cases & $100 \%$ \\
\hline Lower calyx & 50 cases & 50 cases & 48 cases & $96 \%$ \\
\hline
\end{tabular}

Table V : Result of ESWL for Ureteric stones $(n=100)$

\begin{tabular}{|l|c|c|c|c|}
\hline $\begin{array}{l}\text { Period of } \\
\text { ESWL }\end{array}$ & $\begin{array}{c}\text { No of } \\
\text { cases }\end{array}$ & $\begin{array}{c}\text { Totally } \\
\text { fragmented }\end{array}$ & $\begin{array}{c}\text { Success } \\
\text { rate }\end{array}$ & $\begin{array}{c}\text { Failure } \\
\text { rate }\end{array}$ \\
\hline 1 st session & 100 cases & 80 cases & $80 \%$ & $20 \%$ \\
\hline 2nd session & 20 cases & 10 cases & $90 \%$ & $10 \%$ \\
\hline 3rd session & 10 cases & 10 cases & $100 \%$ & $00 \%$ \\
\hline Total cases & 100 cases & 90 cases & $90 \%$ & $10 \%$ \\
\hline
\end{tabular}

Among the 100 ureteric stones, 60 were upper ureteric stone, 20 were mid ureteric and 20 were lower ureteric stone.

Among the 60 cases of upper ureteric stone 54 $(90 \%)$ cases are totally fragmented, so the clearance rate is $90 \%$.Among $\therefore 20$ cases of mid ureteric stone 18 cases were totally fragmented, so the clearance rate is $90 \%$.Among the 20 cases of lower ureteric stones, 14 cases are totally fragmented, so the clearance rate is $70 \%$.

Table VI : Result of ESWL for upper and lower ureteric stone $(\mathrm{n}=100)$

\begin{tabular}{|l|c|c|c|}
\hline Site of stone & $\begin{array}{c}\text { No of } \\
\text { cases }\end{array}$ & $\begin{array}{c}\text { Total } \\
\text { fragmentation }\end{array}$ & $\begin{array}{c}\text { Clearance } \\
\text { rate }\end{array}$ \\
\hline Upper Ureter & 60 cases & 54 cases & $90 \%$ \\
\hline Mid ureter & 20 cases & 18 cases & $90 \%$ \\
\hline Lower ureter & 20 cases & 14 cases & $70 \%$ \\
\hline
\end{tabular}

Lowest stone size of this study was $7 \mathrm{~mm}$ and the biggest one was of $40 \mathrm{~mm}$. Average stone size was $23.5 \mathrm{~mm}$.
Table VII : Stone size in this study.

\begin{tabular}{|c|c|c|c|}
\hline sl. no & size of stone & No of cases & Percentage \\
\hline 1 & $<2 \mathrm{~cm}$ & 400 cases & $80 \%$ \\
\hline 2 & $2-3 \mathrm{~cm}$ & 50 cases & $10 \%$ \\
\hline 3 & $>3 \mathrm{~cm}$ & 50 cases & $10 \%$ \\
\hline Total & & 500 cases & $100 \%$ \\
\hline
\end{tabular}

Both the C-arm and Ultrasound were used to localize the stone. C-arm was used in 400 cases $(80 \%)$ and ultrasound was used for localizing 100 case $(20 \%)$.

Table VIII : Result of C-arm versus ultrasound localization of stones $(n=500)$

\begin{tabular}{|l|r|r|l|}
\hline $\begin{array}{l}\text { Imaging } \\
\text { used }\end{array}$ & $\begin{array}{l}\text { No of } \\
\text { cases }\end{array}$ & $\begin{array}{c}\text { No of total } \\
\text { fragmentation } \\
\text { Success }\end{array}$ & rate \\
\hline C-arm & 400 & 400 & $100 \%$ \\
\hline Ultrasound & 100 & 80 & $80 \%$ \\
\hline
\end{tabular}

Patients included in this study were from different districts of Bangladesh. 400 patients had their present address at Chittagong districts, though they may not be the permanent resident of Chittagong district. 100 patients were only from three hilly districts of Chittagong.Rest 100 patients were from other districts of Bangladesh like, greater Noakhali, Comilla, B.Baria, Tangail, Kustia, Pabna, Gopalgonj, etc.

Table IX : Territory of stone formation in this study $(\mathrm{n}=500)$

\begin{tabular}{|l|c|c|}
\hline Area of Bangladesh & No of cases & Percentage \\
\hline Chittagong district & 300 cases & $60 \%$ \\
\hline Chittagong Hill tracts & 100 cases & $20 \%$ \\
\hline Outside Chittagong & 100 cases & $20 \%$ \\
\hline
\end{tabular}

Single (Precise) focus is used for 400 patients $(80 \%)$.Both precise and extended focus (duel) focus was used particularly in patients with smaller stones in 100 cases $(20 \%)$.

Table X : Result of use of single focus versus duel focus

\begin{tabular}{|l|c|c|}
\hline Focus used & No of cases & percentage \\
\hline Single focus & 400 cases & $80 \%$ \\
\hline Duel focus & 100 cases & $20 \%$ \\
\hline
\end{tabular}

Complications: All of the patients complain of some degree of pain following ESWL. Minor degree of haematuria haematuria was found in $300(60 \%)$ patients ${ }^{10}$. patients ( $2 \%$ ) developed fever with profuse requiring hospital admission and blood transfusion. 
Table XI : Complications of ESWL reported in this study $(\mathrm{n}=500)$

\begin{tabular}{|c|l|c|c|}
\hline $\begin{array}{c}\text { S1. } \\
\text { no }\end{array}$ & Complications & $\begin{array}{c}\text { No of } \\
\text { cases }\end{array}$ & Percentage \\
\hline 1 & Pain & 500 cases & $100 \%$ \\
\hline 2 & Minor haematuria & 300 cases & $600 \%$ \\
\hline 3 & $\begin{array}{l}\text { Frank haematuria \& fever } \\
\text { requiring hospitalization }\end{array}$ & 10 cases & $2 \%$ \\
\hline
\end{tabular}

In this study JJ stent were used for stones larger than $2 \mathrm{~cm}$, but result was benefiial.

\section{Discussion}

The study was carried out between the period of August 2007 to September 2008. Age of the patient was between 18 to 65 years. With a median age of 41.5 years. In this study only the adult group of patients were included. But ESWL is the first-line treatment for renal and upper ureteral calculi of paediatric age group. However, larger stones which will require several ESWL sessions and consecutively increased number of shock waves are best treated with percutaneous nephrolithotomy plus ESWL. Patients with congenital anomalies necessitating surgical reconstruction are the best candidates for operation. Styrofoam boards were used to protect the lungs in children2.The male female ratio of this series was $3: 1$. In Bangladesh male female ratio of stone disease is $3: 1^{5}$.

In this study stones up to $4 \mathrm{~cm}$ diameter (Not stag horn) were fragmented. But for bigger stones preESWL stenting were done. Though $2 \mathrm{~cm}$ is regarded as rational limit for calculi amenable for ESWL .but larger stones could be fragmented with large dose of ESWL ${ }^{12,13}$.

ESWL is not free from complications. It may cause extensive sub capsular haematoma, parenchymal damage etc. Slowing the rate of shock wave delivery to $30 \mathrm{SW} /$ minute has a dramatic protective effect on the integrity of the kidney vasculature 3 . On the other hand increasing the number of SW, decreases the work time and increases the size of the cavitations. Cavitation is necessary to produce fine passable fragments ${ }^{4}$.

In this study among the 400 cases of renal stones, In 300 cases stones were in upper calyx, all of which were fragmented \& cleared. 150 patients had stones in middle calyx, all of them are fragmented \& cleared. But among the 50 cases of lower calyceal stones, 50 stones were fragmented but only 48 patients were cleared of the stone. so the clearance rate is $96 \%$. Failure in rest $4 \%$ cases were due to calyectasis \& poor drainage due to nondependence as located in lower calyx.

A report on Extra-corporeal shock wave lithotripsy results on 1569 patients in renal units of outpatient departmental clinic. Biosan Istanbul, Turkey showed a stone free rate of $93 \%$. In $3.6 \%$ patients were those with history of surgery and / or anatomical calyceal deformities. $3.4 \%$ were due to insignificant data ${ }^{8}$.

The clearance rate of ESWL is better for renal stone than for ureteric stone. It is almost $100 \%$ for renal stones and $75 \%$ for Ureteric stone ${ }^{7}$.

People who undergo ureteroscopy for the treat ment of ureteric stones achieve a higher stone-free rate, but have more complications and a longer hospital stay ${ }^{5}$.

Use of diuretics with ESWL facilitate fatragmention and clearance of ureteral stone, so diuretics seems to be the safe adjunct to ESWL treatment of ureteral stone and coincides with better result ${ }^{9}$.

In this study the size of the stone ranged from $7 \mathrm{~mm}$ to $40 \mathrm{~mm}$, with an average of $23.5 \mathrm{~mm}$. Bigger size of the stone at presentation was due ignorance \& lack of knowledge of our people. Fragmentation of the stone depend upon the site of the stone, hardness of the stone, eg $7 \mathrm{~mm}$ size VUJ stone required 4000 shockwave for total fragmentation, at energy level of 6 , with total energy of 356 kilocalorie, on the other hand $40 \mathrm{~mm}$ right renal stone required 3600 shock wave at energy level of 6 , with a total energy of 270 kilocalorie.

In this study, no local or general anaesthesia were used, only I/V NSAID (IV Ketoralac) was used. Use of EMLA (Eutectic mixture of local anaesthetic) is not better than IV analgesic ${ }^{10}$.

In this study both $\mathrm{C}$-arm and ultrasound are used to localize the stone. The perfection of localization and success rate of fragmentation is better by $\mathrm{C}$-arm than by Ultrasound. this may be due due to lack of experience in ultrasound. In this sudy JJ stent were used for larger stones $(>2 \mathrm{~cm})$. If the patient has a high prabability of steinstrasse close follow up or prophylactic pre-ESWL stenting is indicated ${ }^{11}$.

\section{Conclusion}

ESWL is the gold standard treatment for the urinary stones smaller than $2 \mathrm{~cm}$. The efficacy of ESWL is better for renal stones than for ureteric stones. Among the ureter the result is better for upper 
ureteric stone than for lower ureteric stone.URS and ICPL may be alternatives of ESWL for lower ureteric stone. C-arm localization is better for localization and fragmentation than ultrasound for urinary stones.EWSL for stones larger than $2 \mathrm{~cm}$ is effective. But in that case stenting may be beneficial.

\section{References}

1. Willey publishing inc. Webster's New world Medical Dictionary; 3rd edition: 431

2. Alessandro D'Addessi, Francesco Sasso et al, Journal of End urology, Jan 1, 2008; 22(1): 1-12

3. Andrew P. Evan, James A.McAteer, Bret A. et al. Renal Injury during shock wave lithotripsy is significantly reduced by slowing the rate of shock wave delivery.British Journal of Urology. Sept 2007; 100(3): 624-628

4. C. Dawson, H. Whitfield, British Journal of Urology. 1994; 74: 397

5. M.A.Salam.Principle and practice of Urology;1st edition : 721

6. Lange medical series.Smith General Urology; 16th edition : 256

7. Nabi G, Downey P, Keeley F, Watson G, McClinton SExtra-corporeal shock wave lithotripsy (ESWL) versus ureteroscopic management for ureteric calculi. J of Urology; Jan/2007: 44-45

8. Tolon M. Miroglu C, Erol H.Et al. A report on Extra-cor poreal shock wave lithotripsy results on 1569 patients in renal units of outpatient departmental clinic. Biosan Istanbul, Turkey. J urol. 1991/Apr; 145: 695-698

9. A zomorrodi, J Golivandan, J Samadi. Result of use of diuretics with ESWL. Saudi Journal of Kidney diseases and transplantation. Jan/2008; 19(3): 394-400

10. P. F. Mc Donald, A. Nafees \& A.M.Berry. Use of tropical analgesia for ESWL. British journal of anaesthesia. $69 ; 4: 399-400$

11. K Madbouly, KZ Sheir, E Elsobky et al . Risk Factors for the formation of steinstrasse after ESWL. The Journal of Urology/2002; 167(3): 1239-1242

12. H. Augustin .Prediction of ston free rate after ESWL. Journal of Europian Urology/2007; 52(2): $318-320$
13. AM Mosli H. MA Farsi H. AL Zimaity MF. A study of urinary stones requiring large dose of ESWL treatment Saudi Medical Journal/ 1996; 17: 726-731

Department of Urology, King Abdul Aziz University Hospital, Jeddah, Saudi Arabia. 